\title{
Facile Hydrothermal Approach to ZnO Nanorods at Mild Temperature
}

\author{
Yang Jiao, Yang Liu, Bosi Yin, Siwen Zhang, Fengyu Qu, Xiaodan Wu, and Xiang Wu \\ Key Laboratory for Photonic and Electronic Bandgap Materials, Ministry of Education, College of Chemistry and Chemical Engineering, \\ Harbin Normal University, Harbin 150025, China
}

Correspondence should be addressed to Xiang Wu; wuxiang05@gmail.com

Received 26 June 2013; Accepted 9 July 2013

Academic Editor: Renzhi Ma

Copyright (C) 2013 Yang Jiao et al. This is an open access article distributed under the Creative Commons Attribution License, which permits unrestricted use, distribution, and reproduction in any medium, provided the original work is properly cited.

In this work, $\mathrm{ZnO}$ nanorods are obtained through a facile hydrothermal route. The structure and morphology of the resultant products are characterized by X-ray diffraction (XRD) and scanning electron microscope (SEM). The experimental results indicated that the as-synthesized $\mathrm{ZnO}$ nanorods have an average diameter of approximate $100 \mathrm{~nm}$. A possible growth mechanism for $\mathrm{ZnO}$ nanorods was proposed based on the experimental results and found that $\mathrm{Zn}$ powder plays a critical role for the morphology of the products. Room temperature photoluminescence property of $\mathrm{ZnO}$ nanorods shows an ultraviolet emission peak at $390 \mathrm{~nm}$.

\section{Introduction}

Recently, Zinc oxide $(\mathrm{ZnO})$ nanostructures have received more attention due to their versatile applications in photoluminescence (PL) [1, 2], field emission [3], and piezoelectronics [4-6]. The one-dimensionality of these structures leads to some of their interesting properties, along with the potential for novel applications. So far, $\mathrm{ZnO}$ nanorods (NWs) [7], nanobelts [8,9], nanotubes [10], nanowindmills [11], hierarchical nanostructures [12-17], and so on have been reported. These nanostructures are potential candidates for UV light sources, sensors [18], and solar cells [19]. Various physical and chemical routes have been used to prepare a wide range of $\mathrm{ZnO}$ nanostructures. Raula et al. reported a simple wet-chemical approach to the growth of hierarchical $\mathrm{ZnO}$ nanostructures with different shapes [20]. Ma's group used carbothermal reduction method to fabricate large-scale $\mathrm{ZnO}$ nanowires [21]. Wang and his coworkers synthesized exotic zigzag $\mathrm{ZnO}$ nanoribbons by thermal evaporation [22]. Liu's group fabricated a highly flexible, sensitive photodetector built on flexible nanoparticle-assembled $\mathrm{ZnO}$ cloth via a carbon cloth templated hydrothermal method [23]. Among these methods, hydrothermal method has been used widely due to its simple, low cost and little pollution.

In recent years, $\mathrm{ZnO}$ semiconductor nanomaterials are regarded as one of the most important photonic materials owing to its direct wide bandgap $(3.37 \mathrm{eV})$ and large excitation binding energy ( $60 \mathrm{meV}$ at room temperature). In this paper, we explore a simple one pot hydrothermal route for the controlled growth of $\mathrm{ZnO}$ nanorods. The morphology, size, and structure of the $\mathrm{ZnO}$ nanorods have been investigated in detail. A possible mechanism has been suggested to explain the formation and growth of the nanorods structures. Room temperature photoluminescence $(\mathrm{PL})$ properties of the asprepared $\mathrm{ZnO}$ products were also investigated.

\section{Experimental}

All reagents were of analytical grade and used without further purification. For the preparation of $\mathrm{ZnO}$ nanomaterials, a typical process was as follows. Firstly, $0.65 \mathrm{~g}$ metallic $\mathrm{Zn}$ powder was added into $10 \mathrm{~mL}$ deionized water with continuous stirring at room temperature. Subsequently, $20 \mathrm{~mL}$ $\mathrm{Zn}(\mathrm{OH})_{4}{ }^{2-}$ solution $\left(2.97 \mathrm{~g} \mathrm{Zn}\left(\mathrm{NO}_{3}\right)_{2}\right.$ and $\left.5.6 \mathrm{~g} \mathrm{KOH}\right)$ was prepared. The mixture was then introduced into a Teflon vessel $(50 \mathrm{~mL}$ capacity) sealed in a stainless-steel autoclave. The autoclave was heated and maintained at the desired temperature $180^{\circ} \mathrm{C}$ for $5 \mathrm{~h}$ and then cooled to room temperature. The white product was collected and rinsed with deionized water and ethanol and was finally purified by selfsedimentation. Finally the product was dried in a chamber at $80^{\circ} \mathrm{C}$ for $5 \mathrm{~h}$ 


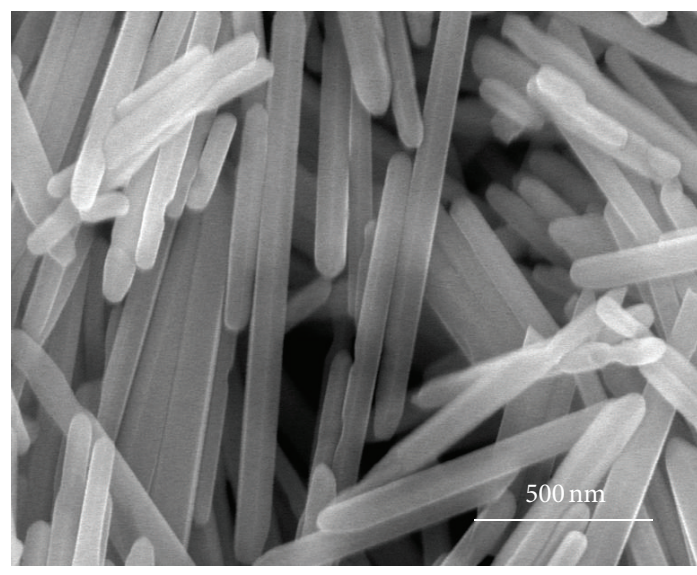

(a)

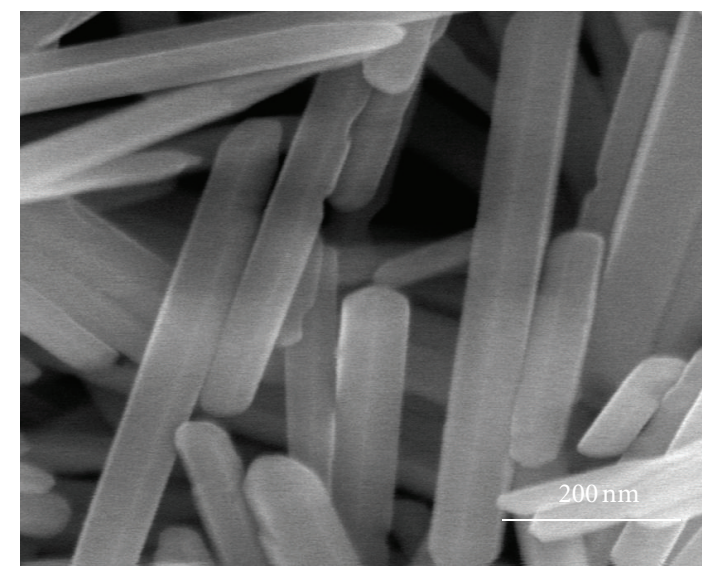

(b)

FIGURE 1: SEM images of ZnO nanorods (a) low magnification SEM image and (b) high magnification SEM image.

The obtained product was characterized by scanning electron microscope (SEM, Hitachi-4800), X-ray powder diffraction (XRD, Rigaku Dmax-2600/pc, Cu K $\alpha$ radiation, $\lambda=0.1542 \mathrm{~nm}, 40 \mathrm{KV}$, and $100 \mathrm{~mA})$. Optical property of the as-synthesized $\mathrm{ZnO}$ nanostructures was investigated by a standard UV-VIS-NIR spectrophotometer (JASCO V-670).

\section{Results and Discussion}

Low magnification SEM image (Figure 1(a)) presents the overall morphology of the as-synthesized samples, clearly observing that as-prepared samples consisted of many nanorods. Further observation finds that the diameter of nanorods is about $100 \mathrm{~nm}$ as shown in Figure 1(b). Figure 2 shows XRD pattern of the as-obtained product. All of the diffraction peaks are in accordance with the standard bulk $\mathrm{ZnO}$ pattern (JCPDS number 36-1451) and can be straightforwardly indexed to hexagonal wurtzite type $\mathrm{ZnO}$. No peaks of other phases were detected, indicating high purity of the as-synthesized product. The strong and sharp peaks indicate that the as-prepared product is highly crystalline.

To investigate the formation mechanism of the asprepared $\mathrm{ZnO}$ products, a series of controlled experiments were conducted. First, keeping the other growth parameters constant, no addition of $\mathrm{Zn}$ power, and the shape of the as-obtained $\mathrm{ZnO}$ products are not regular, and some of the products are small particles, as shown in Figures 3(a) and 3(b). Figures 3(c) and 3(d) showed the SEM images of the product without addition of $\mathrm{Zn}\left(\mathrm{NO}_{3}\right)_{2}$, revealing that as-prepared samples consisted of many nanorods, but the nanorods are uneven, demonstrating that $\mathrm{Zn}$ powder plays a very important role in the formation of nanorods. The above results indicate that tailoring the growth parameters deliberately is essential to obtain the desiring nanostructures. Based on the above experiment results, a possible growth mechanism for $\mathrm{ZnO}$ nanorods may be proposed as follows:

$$
\begin{gathered}
\mathrm{Zn}+4 \mathrm{OH}^{-} \longrightarrow \mathrm{ZnO}_{2}{ }^{2-}+2 \mathrm{H}_{2} \mathrm{O}, \\
\mathrm{ZnO}_{2}{ }^{2-}+\mathrm{H}_{2} \mathrm{O} \longrightarrow \mathrm{ZnO}+2 \mathrm{OH}^{-},
\end{gathered}
$$

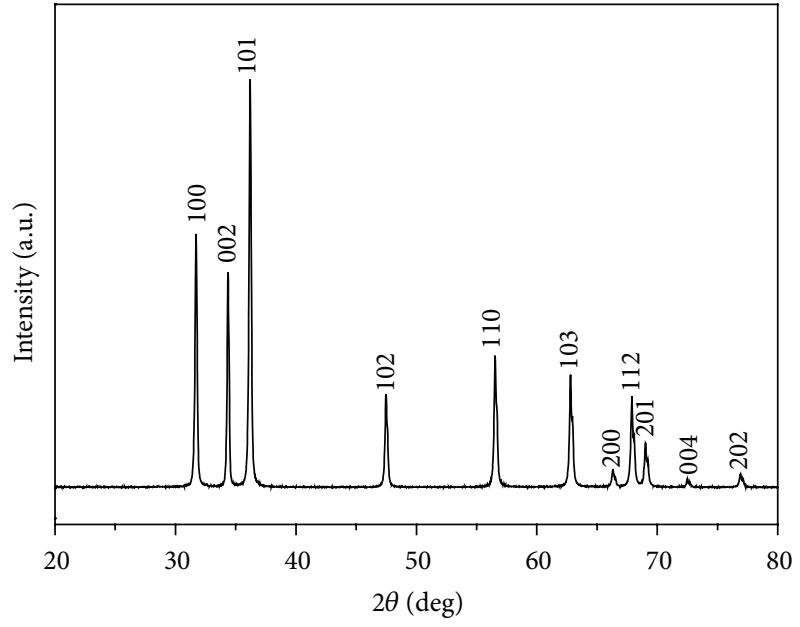

FIGURE 2: XRD pattern of the as-synthesized samples.

$$
\begin{gathered}
\mathrm{Zn}^{2+}+2 \mathrm{OH}^{-} \longrightarrow \mathrm{Zn}(\mathrm{OH})_{2} \\
\mathrm{Zn}(\mathrm{OH})_{2}+2 \mathrm{OH}^{-} \longrightarrow \mathrm{Zn}(\mathrm{OH})_{4}{ }^{2-} \\
\mathrm{Zn}(\mathrm{OH})_{4}{ }^{2-} \longrightarrow \mathrm{ZnO}+2 \mathrm{H}_{2} \mathrm{O}+2 \mathrm{OH}^{-}
\end{gathered}
$$

In the initial stage, $\mathrm{Zn}^{2+}$ and $\mathrm{OH}^{-}$react with each other to form $\mathrm{ZnO}_{2}{ }^{2-}$ and $\mathrm{Zn}(\mathrm{OH})_{2}$, respectively. Because of an excess of alkali, $\mathrm{Zn}(\mathrm{OH})_{2}$ will further react with $\mathrm{OH}^{-}$to form $\mathrm{Zn}(\mathrm{OH})_{4}{ }^{2-}$. During the stage of hydrothermal condition, $\mathrm{ZnO}_{2}{ }^{2-}$ and $\mathrm{Zn}(\mathrm{OH})_{2}$ will turn to $\mathrm{ZnO}$ small particles. These particles have a tendency to aggregate due to large surface energy. Surface energy is substantially reduced when the neighboring nanoparticles are grown [24]. With the crystal growth continuing, each nanoparticle in the aggregates or nanorods has its own orientation and acts as a nucleus for further growth. These growth processes are not only related to the anisotropic $\mathrm{ZnO}$ crystal structure but also the involved reaction conditions. The growth habit of $\mathrm{ZnO}$ crystals can 


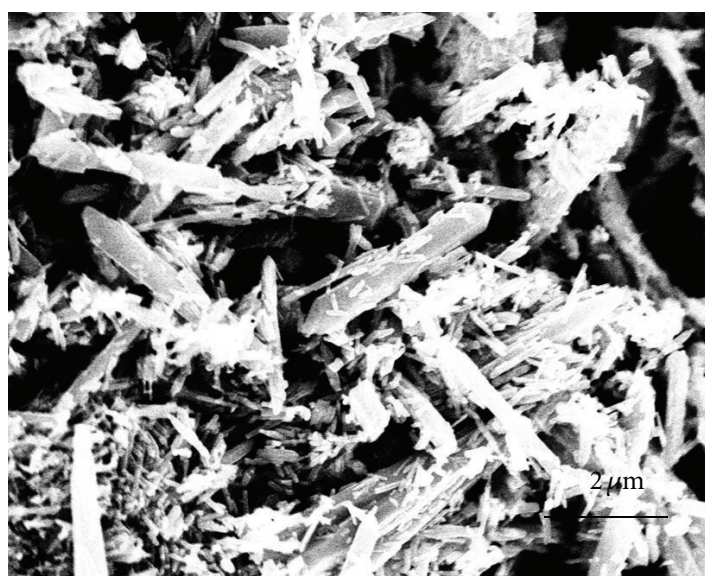

(a)

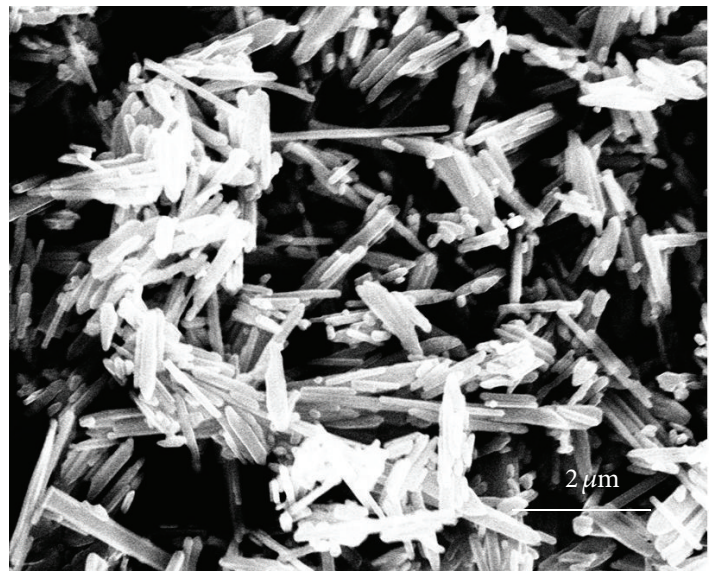

(c)

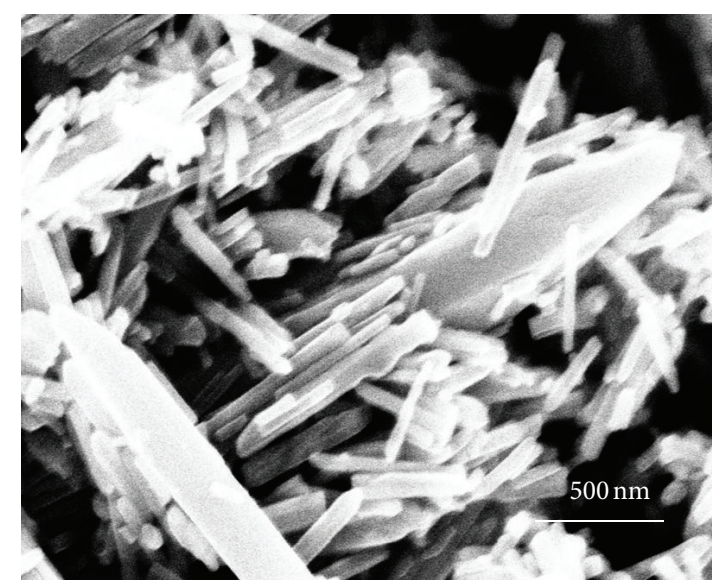

(b)

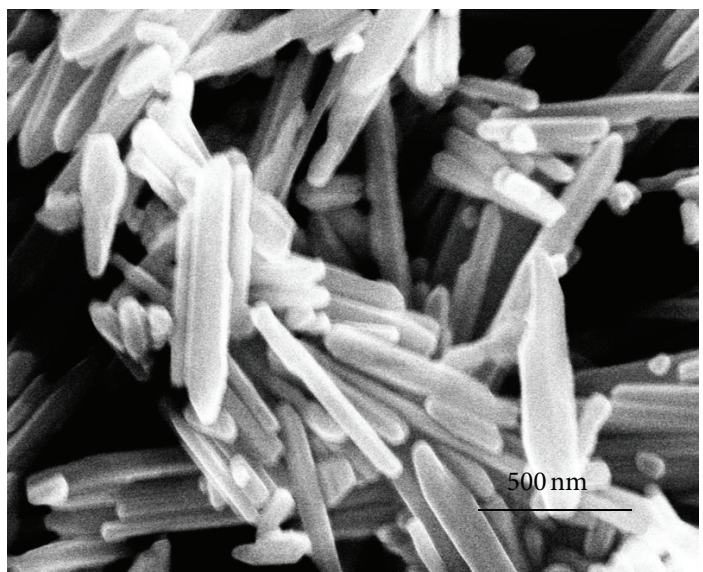

(d)

FIGURE 3: SEM images of the products at different experiment parameters ((a)-(b)) without the addition of Zn powder and ((c)-(d)) the addition of $\mathrm{Zn}$ powder, without the addition of $\mathrm{Zn}\left(\mathrm{NO}_{3}\right)_{2}$

control the $\mathrm{ZnO}$ crystals to grow into the nanorods. Without $\mathrm{Zn}$ powder, the morphology of the products is irregular. $\mathrm{Zn}$ powder provides enough $\mathrm{Zn}$ resource to induce $\mathrm{ZnO}$ nanoparticles further growth into the nanorods according to the experiment results. Figure 4 demonstrates a growth schematic for the as-synthesized $\mathrm{ZnO}$ nanorods.

Finally, room temperature photoluminescence property of the as-synthesized $\mathrm{ZnO}$ nanorods was investigated. Figure 5 presents a PL spectrum of the as-synthesized products. The spectrum reveals a sharp emission band located at $390 \mathrm{~nm}$. The UV band gap emission results from the radiative recombination of an excited electron in the conduction band $\left(\mathrm{e}_{\mathrm{CB}}{ }^{-}\right)$with the valence band hole $\left(\mathrm{h}_{\mathrm{VB}}{ }^{+}\right)$. It can be commonly assigned as the near band gap exciton emission in $\mathrm{ZnO}$ [25]. The visible (or deep trap) photoluminescence (PL) is commonly defined as the recombination of the electronhole pair from localized states with energy levels deep in the band gap, resulting in lower energy emission. These alternate energy levels are usually attributed to dopants, structural features, or surface defects, such as singly ionized oxygen vacancies, zinc vacancies, and zinc interstitials, or extrinsic impurities [26-29].

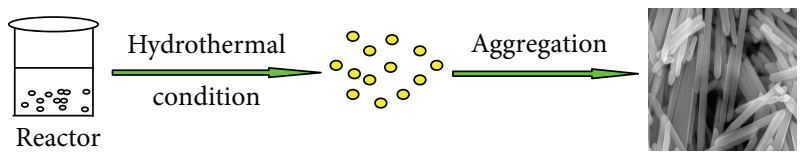

FIGURE 4: Growth Schematic of the as-synthesized $\mathrm{ZnO}$ nanorods.

\section{Conclusion}

$\mathrm{ZnO}$ nanorods with high yield have been successfully obtained by a simple hydrothermal approach. The average diameter of the as-synthesized nanorods is about $100 \mathrm{~nm}$. The possible growth mechanism of the $\mathrm{ZnO}$ nanosheets is proposed based on the experimental results. Room temperature photoluminescence spectrum demonstrates that $\mathrm{ZnO}$ nanorods show a strong and sharp UV band edge emission peak at $390 \mathrm{~nm}$. It is expected that such $\mathrm{ZnO}$ nanorods may have applications in optoelectronic micro/nanodevices.

\section{Acknowledgments}

This work was supported by the Foundation for Key Project of Ministry of Education, China (no. 211046), Program for 


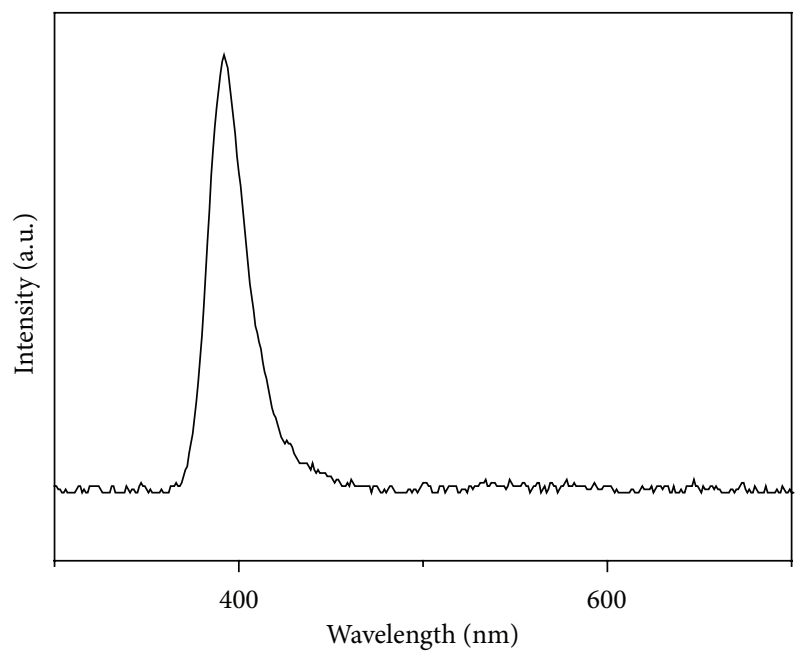

FIGURE 5: Room temperature photoluminescence spectrum of the as-synthesized $\mathrm{ZnO}$ nanorods.

New Century Excellent Talents in Heilongjiang Provincial University (1252-NCET-018), the Scientific Research Fund of Heilongjiang Provincial Education Department (12531179, 12511168), Youth Skeleton Teacher Fund of Harbin Normal University (KGB201014), and Program for Scientific and Technological Innovation Team Construction in Universities of Heilongjiang (no. 2011TD010).

\section{References}

[1] L. J. Yu, F. Y. Qu, and X. Wu, "Facile hydrothermal synthesis of novel ZnO nanocubes," Journal of Alloys and Compounds, vol. 504, no. 1, pp. L1-L4, 2010.

[2] L. H. Gong, X. Wu, C. Ye, F. Qu, and M. An, "Aqueous phase approach to $\mathrm{ZnO}$ microspindles at low temperature," Journal of Alloys and Compounds, vol. 501, no. 2, pp. 375-379, 2010.

[3] C. J. Lee, T. J. Lee, S. C. Lyu, Y. Zhang, H. Ruh, and H. J. Lee, "Field emission from well-aligned zinc oxide nanowires grown at low temperature," Applied Physics Letters, vol. 81, no. 19, pp. 3648-3650, 2002.

[4] J. Zhou, P. Fei, Y. F. Gao et al., "Mechanical-electrical triggers and sensors using piezoelectric micowires/nanowires," Nano Letters, vol. 8, no. 9, pp. 2725-2730, 2008.

[5] Z. L. Wang and J. H. Song, "Piezoelectric nanogenerators based on zinc oxide nanowire arrays," Science, vol. 312, no. 5771, pp. 243-246, 2006.

[6] Y. F. Gao and Z. L. Wang, "Electrostatic potential in a bent piezoelectric nanowire. The fundamental theory of nanogenerator and nanopiezotronics," Nano Letters, vol. 7, no. 8, pp. 24992505, 2007.

[7] H. J. Zhang, X. Wu, F. Y. Qu, and G. G. Zhao, "ZnO microrod arrays grown on a curved sphere surface and their optical properties," CrystEngComm, vol. 13, no. 20, pp. 6114-6117, 2011.

[8] P. X. Gao, Y. Ding, W. Mai, W. L. Hughes, C. S. Lao, and Z. L. Wang, "Materials science: conversion of zinc oxide nanobelts into superlattice-structured nanohelices," Science, vol. 309, no. 5741, pp. 1700-1704, 2005.

[9] Z. W. Pan, Z. R. Dai, and Z. L. Wang, "Nanobelts of semiconducting oxides,” Science, vol. 291, no. 5510, pp. 1947-1949, 2001.
[10] H. B. Chen, X. Wu, L. H. Gong, C. Ye, F. Y. Qu, and G. Z. Shen, "Hydrothermally grown $\mathrm{ZnO}$ micro/nanotube arrays and their properties," Nanoscale Research Letters, vol. 5, no. 3, pp. 570-575, 2010.

[11] L. J. Yu, F. Y. Qu, and X. Wu, "Solution synthesis and optimization of $\mathrm{ZnO}$ nanowindmills," Applied Surface Science, vol. 257, no. 17, pp. 7432-7435, 2011.

[12] H. J. Zhang, R. F. Wu, Z. W. Chen, G. Liu, Z. N. Zhang, and $\mathrm{Z}$. Jiao, "Self-assembly fabrication of $3 \mathrm{D}$ flower-like $\mathrm{ZnO}$ hierarchical nanostructures and their gas sensing properties," CrystEngComm, vol. 14, no. 5, pp. 1775-1782, 2012.

[13] X. Wu, P. Jiang, W. Cai, X. D. Bai, P. Gao, and S. S. Xie, "Hierarchical $\mathrm{ZnO}$ micro-/nano-structure film," Advanced Engineering Materials, vol. 10, no. 5, pp. 476-481, 2008.

[14] Y. Lei, X. Wu, and F. Y. Qu, "Synthesis and characterization of flower-like $\mathrm{ZnO}$ microspheres assembled by nanosheets," Advanced Science Letters, vol. 4, no. 11-12, pp. 3608-3612, 2011.

[15] Y. Lei, F. Y. Qu, and X. Wu, "Assembling $\mathrm{ZnO}$ nanorods into microflowers through a facile solution strategy: morphology control and cathodoluminescence properties," Nano-Micro Letters, vol. 4, no. 1, pp. 45-51, 2012.

[16] X. Wu, W. Cai, and F. Y. Qu, "Spontaneous formation of single crystal ZnO nanohelices," Chinese Physics B, vol. 18, no. 4, pp. 1669-1673, 2009.

[17] X. Wu, W. Cai, and F. Y. Qu, "Tailoring the morphology and wettability of $\mathrm{ZnO}$ one-dimensional nanostructures," Acta Physica Sinica, vol. 58, no. 11, pp. 8044-8049, 2009.

[18] Z. Yang, L. M. Li, Q. Wan, Q. H. Liu, and T. H. Wang, "Highperformance ethanol sensing based on an aligned assembly of $\mathrm{ZnO}$ nanorods," Sensors and Actuators B, vol. 135, no. 1, pp. 5760, 2008.

[19] C. K. Xu, P. Shin, L. L. Cao, and D. Gao, "Preferential growth of long $\mathrm{ZnO}$ nanowire array and its application in dye-sensitized solar cells," Journal of Physical Chemistry C, vol. 114, no. 1, pp. 125-129, 2010.

[20] M. Raula, M. H. Rashid, T. K. Paira, E. Dinda, and T. K. Mandal, "Ascorbate-assisted growth of hierarchical $\mathrm{ZnO}$ nanostructures: sphere, spindle, and flower and their catalytic properties," Langmuir, vol. 26, no. 11, pp. 8769-8782, 2010.

[21] C. Y. Ma, Z. H. Zhou, H. Wei, Z. Yang, Z. M. Wang, and Y. F. Zhang, "Rapid large-scale preparation of $\mathrm{ZnO}$ nanowires for photocatalytic application," Nanoscale Research Letters, vol. 6, article 536, 2011.

[22] L. Wang, K. Z. Chen, and L. F. Dong, "Synthesis of exotic zigzag $\mathrm{ZnO}$ nanoribbons and their optical, electrical properties," Journal of Physical Chemistry C, vol. 114, no. 41, pp. 17358-17361, 2010.

[23] B. Liu, Z. R. Wang, Y. Dong et al., "ZnO-nanoparticleassembled cloth for flexible photodetectors and recyclable photocatalysts," Journal of Materials Chemistry, vol. 22, no. 18, pp. 9379-9384, 2012.

[24] J. Lian, Z. M. Ding, F. Kwong, and D. H. L. Ng, “Templatefree hydrothermal synthesis of hexagonal $\mathrm{ZnO}$ micro-cups and micro-rings assembled by nanoparticles," CrystEngComm, vol. 13, no. 15, pp. 4820-4822, 2011.

[25] K. Vanheusden, W. L. Warren, C. H. Seager, D. R. Tallant, J. A. Voigt, and B. E. Gnade, "Mechanisms behind green photoluminescence in $\mathrm{ZnO}$ phosphor powders," Journal of Applied Physics, vol. 79, no. 10, pp. 7983-7990, 1996.

[26] V. Chakrapani, C. Pendyala, K. Kash, A. B. Anderson, M. K. Sunkara, and J. C. Angus, "Electrochemical pinning of the fermi 
level: mediation of photoluminescence from gallium nitride and zinc oxide," Journal of the American Chemical Society, vol. 130, no. 39, pp. 12944-12952, 2008.

[27] R. Dingle, "Luminescent transitions associated with divalent copper impurities and the green emission from semiconducting zinc oxide," Physical Review Letters, vol. 23, no. 11, pp. 579-581, 1969.

[28] X. Wu, H. B. Chen, L. H. Gong, F. Y. Qu, and Y. F. Zheng, "Low temperature growth and properties of $\mathrm{ZnO}$ nanorod arrays," Advances in Natural Sciences: Nanoscience and Nanotechnology, vol. 2, no. 3, Article ID 035006, 2011.

[29] B. X. Jia, W. N. Jia, J. Wang, F. Y. Qu, and X. Wu, "Growth of thin sheet assembled hierarchical $\mathrm{ZnO}$ nanostructures," Journal of Nanomaterials, vol. 2012, Article ID 796815, 5 pages, 2012. 

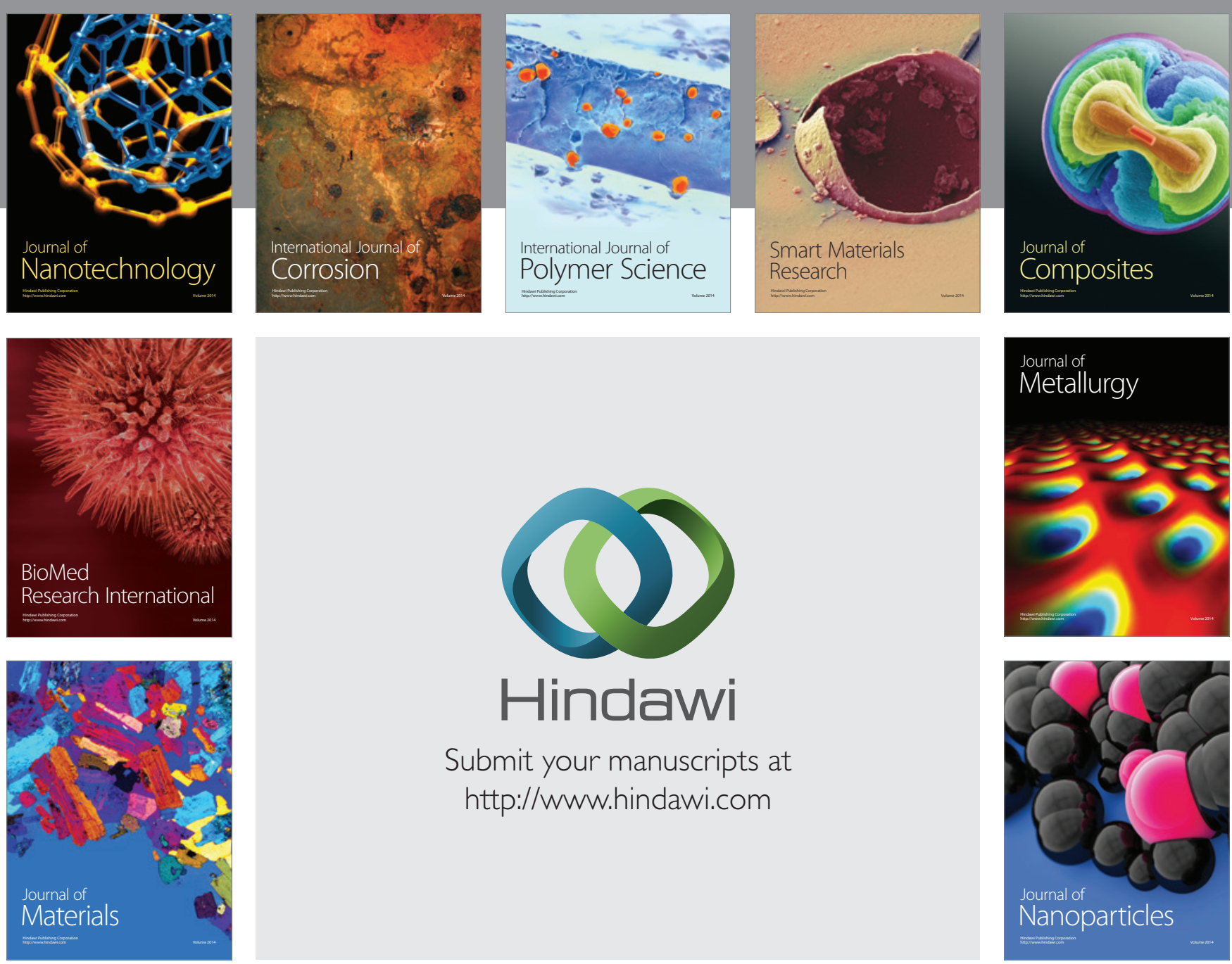

Submit your manuscripts at http://www.hindawi.com
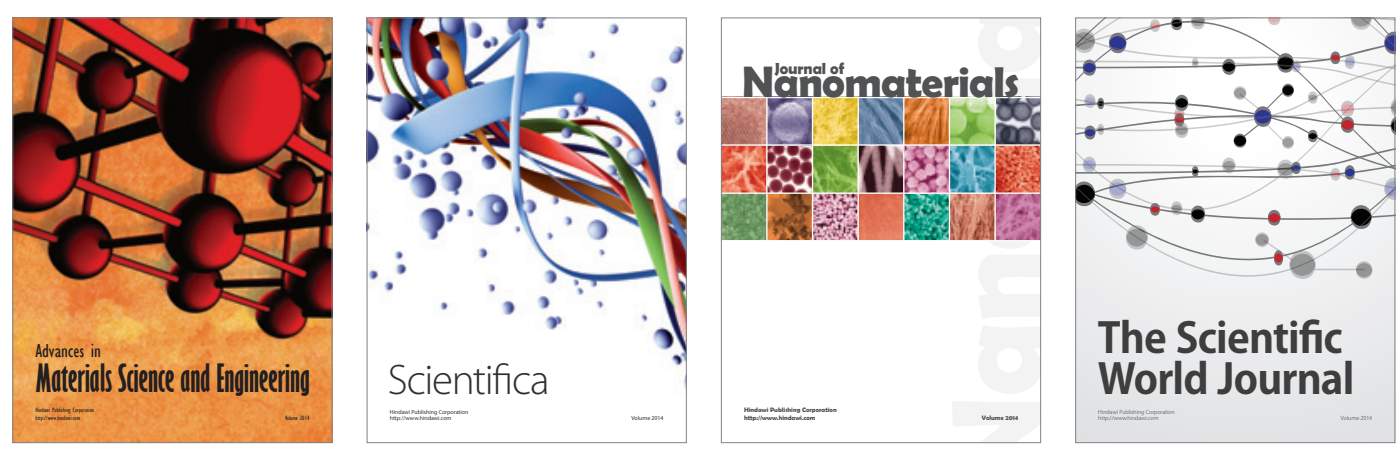

\section{The Scientific World Journal}
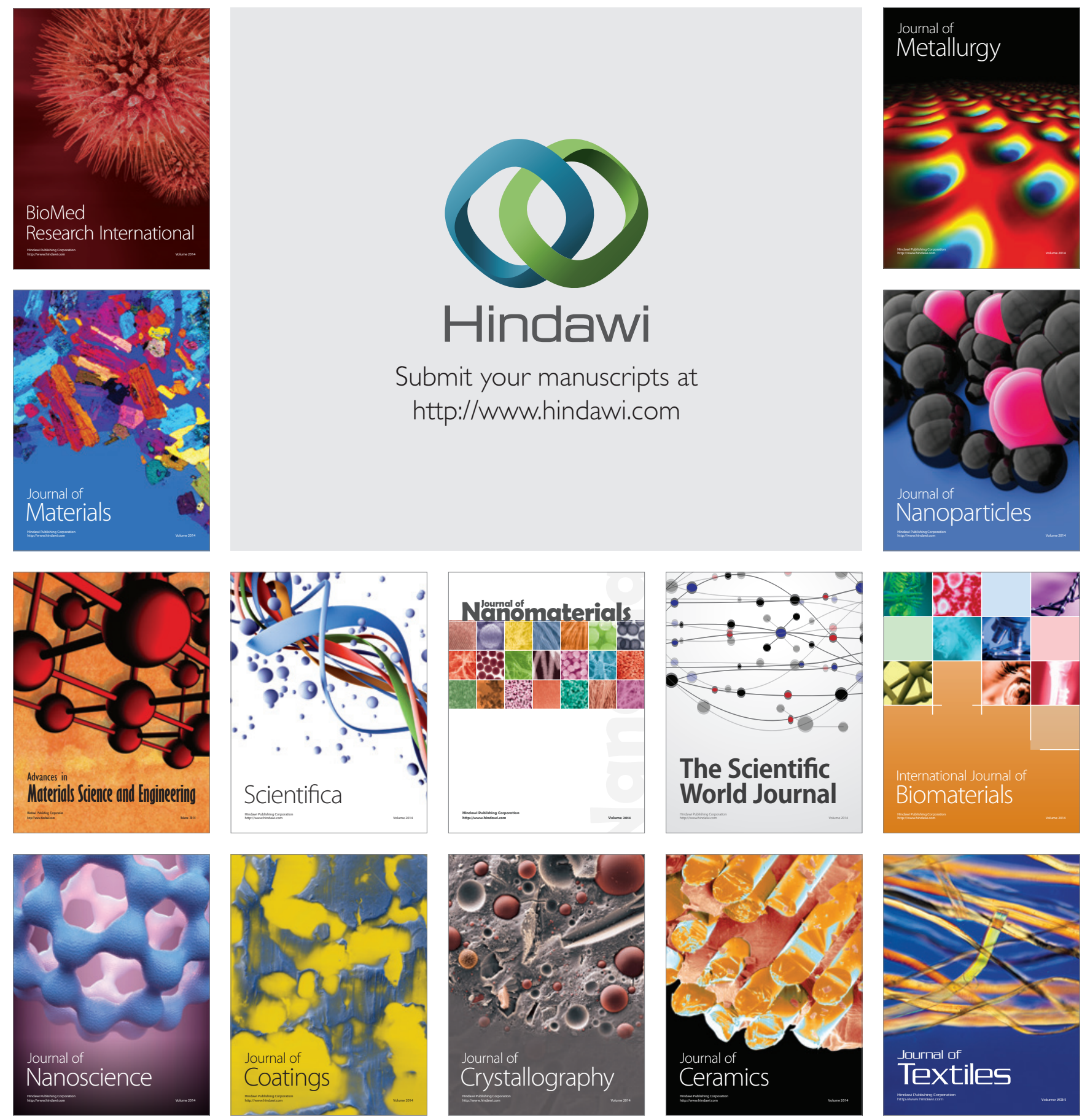